\title{
Antínoo(S) e Antinous: Da reinterpretação de Antínoo no poema homônimo de Fernando Pessoa
}

\author{
Igor Lemos Moreira ${ }^{1}$ \\ Vítor M. Costa ${ }^{2}$
}

Resumo: O presente trabalho busca, através da História Cultural e da Hermenêutica, realizar uma análise do poema Antinous (1918), publicado pela primeira vez em língua inglesa por Fernando Pessoa. Dividido em duas partes, propõe-se inicialmente uma reflexão acerca do uso de fontes literárias para as pesquisas e estudos na área de História partindo das propostas da historiografia francesa. Na segunda parte do texto, é realizada uma análise seguida de algumas considerações interpretativas acerca do texto de Pessoa sob a ótica da hermenêutica e dos estudos da linguagem, relacionando sua escrita ao período vivido pelo escritor e às narrativas acerca do personagem Antínoo.

Palavras-chave: Fernando Pessoa, Antínoo, Hermenêutica, Literatura, Poesia.

Abstract: The present work seeks, through Cultural History and Hermeneutics, to analyze the poem Antinous (1918), first published in English by Fernando Pessoa. Divided in two parts, it is initially proposed a reflection on the use of literary sources for research and studies in the area of History based on the proposals of French historiography. In the second part of the text, an analysis is carried out followed by some interpretive considerations about the text of Pessoa under the optics of hermeneutics and of the studies of the language, relating his writing to the period lived by the writer and the narratives about the character Antinous.

Keywords: Fernando Pessoa, Antinous, Hermeneutics, Literature, Poetry.

${ }^{1}$ Mestrando no Programa de Pós-Graduação em História da Universidade do Estado de Santa Catarina. Bolsista CAPES-DS e integrante do Laboratório de Imagem e Som (LIS/UDESC).

${ }^{2}$ Mestrando em Filosofia pela Universidade Federal de Santa Catarina (UFSC). Bolsista CAPES. Graduado em História pela mesma instituição e membro do Núcleo de Filosofia Antiga da UFSC.

Revista Vernáculo n. ${ }^{\circ} 41$ - primeiro semestre /2018

ISSN 2317-4021 
O uso de fontes literárias para as pesquisas e estudos na área de História trata-se de uma das marcas na renovação da historiografia ocorrida no século $\mathrm{XX}^{3}$. Se, de um lado, no século XIX, observamos a consolidação da História enquanto disciplina autônoma, dedicada à análise e estudo de fontes tomadas enquanto registro dos fatos que confeririam uma suposta "verdade histórica"; de outro, conforme Le $\mathrm{Goff}^{4}$, a partir deste mesmo período, especialmente com a escola positivista, o documento - esse, essencialmente escrito - passa a ser o fundamento do fato histórico, passando a ser considerado o meio pelo qual se comprovava oque houvera acontecido e averiguava a argumentação dos historiadores. Ou seja, o documento tornava-se indispensável ao historiador.

Neste período, ainda se observa uma prevalência da noção de documento e monumento enquanto sinônimos, não a esmo grandes coleções de documentos eram chamadas de monumentos. A associação do documento enquanto algo escrito de caráter oficial — um registro de como o passado "realmente aconteceu", para remeter aos tucididianos alemães - prevalecerá em maior ou menor escala até 1929, quando os fundadores da revista Annales passam a insistir numa ampliação desta noção ${ }^{5}$, afirmando que a história se faz de documentos escritos, mas

${ }^{3}$ FERREIRA, Antonio Celso . A fonte fecunda . In: PINSKY, Carla; LUCA, Tânia (orgs.). O historiador e suas fontes. São Paulo: contexto, 2009.

${ }^{4}$ LE GOFF, Jacques. Documento/Monumento. In: LE GOFF, Jacques. História e Memória. 5. ed. Campinas: Ed. Unicamp, 2003.

${ }^{5}$ BURKE, Peter. A Escola dos Annales (1929-1989): a Revoluçã o Francesa da Historiografia. São Paulo: Fundação Editora da UNESP, 1997.

Revista Vernáculo n. ${ }^{\circ} 41$ - primeiro semestre /2018

ISSN 2317-4021 
apenas quando esses estão disponíveis, do contrário, outras fontes fazem-se necessárias. Porém tais propostas só irão ser empreendidas com maior empenho a partir da década de 1960 - momento que podemos chamar de "Explosão do documento".

A partir das propostas dos Annales, o que se refere ao significado de documento passa por transformações, tanto de maneira qualitativa quanto quantitativa, principalmente por um interesse da historiografia em não priorizar tanto os "grandes homens" ou "grandes eventos", 6 mas ver a história por várias dimensões. Contudo, essa expansão da noção de documento colocou um ponto central para a pesquisa histórica: o documento deve estar submetido sempre a uma crítica radical, deve ser posto em dúvida, e encarado também enquanto um elemento duvidoso ${ }^{7}$. Tal questão leva-nos para outro ponto importante relacionado à noção de documento e monumento, qual seja: o de que, enquanto no século XIX, como já citado, o princípio da história seria o documento, aquele que conduz e atesta as produções históricas, por outro lado, no século XX - especialmente através das produções dos Annales e da renovação documental - a principal questão para o historiador será o "problema".

Ora, tais discussões sobre o estatuto do documento para a história e historiografia, partindo de novos problemas, novas abordagens e novos objetos, levaram os historiadores a lidarem mais de

${ }^{6}$ Observa-se, anteriormente aos Annales, propostas semelhantes na historiografia social inglesa no que se refere à atenção às coletividades.

${ }^{7}$ SIRINELLI, Jean-François. Abrir a história: novos olhares sobre o século XX francês. Belo Horizonte: Autêntica, 2014.

Revista Vernáculo n. ${ }^{\circ} 41$ - primeiro semestre $/ 2018$

ISSN 2317-4021 
perto com uma série de outros campos e possibilidades — entre esses, a literatura. Ferreira ${ }^{8}$ considera que as ambições dos historiadores pelos estudos dos processos sociais e econômicos levaram à utilização não apenas de novos tipos de fontes, mas também de abordagens interdisciplinares. Entre os campos historiográficos citados pelo autor, e que inauguram espaços para a investigação de textos literários, encontra-se a História Cultural.

A História Cultural, segundo o historiador francês Roger Chartier, constituiu-se enquanto modo de reflexão acerca da cultura como um conjunto de significados atribuídos e compartilhados pelos homens para dar sentido e razão ao seu mundo. Esse campo "tem por principal objeto identificar o modo como em diferentes lugares e momentos uma determinada realidade social é construída, pensada, dada a ler"9 . Nessa perspectiva podemos considerar que suas principais preocupações estão concentradas em identificar os modos pelos quais determinadas épocas e/ou sujeitos representavam seu mundo cultural, seus "modos de concepção do real".

Com efeito, o uso da literatura enquanto fonte para os estudos na historiografia surge como um meio profícuo e especial de análise. Assim, para a historiadora Sandra Pesavento,

${ }^{8}$ FERREIRA, Antonio Celso. A fonte fecunda. In: PINSKY, Carla; LUCA, Tânia (orgs.). O historiador e suas fontes. São Paulo: contexto, 2009.

${ }^{9}$ CHARTIER, Roger. A história cultural : entre práticas e representações . Portugal: DIFEL, 2002. p. 16.

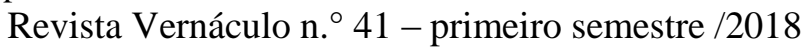


A Literatura ocupa, no caso, a função de traç o, que se transforma em documento e passa a responder as questões formuladas pelo historiador. Não se trata no caso, de estabelecer uma hierarquia entre História e Literatura, mas sim de precisar o lugar de onde se faz a pergunta. ${ }^{10}$

Baseado nisso, consideramos que a literatura possibilita ao historiador questionar-se acerca das visões de mundo de determinados sujeitos ou períodos. Igualmente é fonte privilegiada para o estudo das representações de uma sociedade e, igualmente, de seus projetos de futuro. Outrossim, uma obra literária fornece pistas para que o historiador reflita e problematize os modos de agir e os significados atribuídos ao seu presente, bem como as relações e constituições narrativas de seu passado.

Uma fonte literária, pois, devidamente inserida em seu espaço de produção e recepção, possibilita investigações acerca dos hábitos, práticas e representações sociais de um povo. Afinal, conforme Chartier, a literatura é compartilhada por diversos segmentos sociais, porém em formas e, por vezes, em suportes diferentes. Assim, o autor afirma que a História Cultural, especialmente em seus estudos recentes, encontra-se "preocupada antes de tudo em compreender usos e práticas"11 e, desse modo, a literatura insere-se enquanto fonte privilegiada.

${ }^{10}$ PESAVENTO, Sandra J. História e história cultural . Belo Horizonte : Autêntica, 2014. p. 82.

${ }^{11}$ CHARTIER, Roger. Leituras e leitores na França do Antigo Regime . São Paulo: UNESP, 2004. p. 13.

Revista Vernáculo n. ${ }^{\circ} 41$ - primeiro semestre /2018

ISSN 2317-4021 
Dito isso, o foco do presente artigo detém-se em Fernando Pessoa, mais especificamente em um poema produzido por ele em língua inglesa no início do século XX. Tal poema, intitulado de Antinous, como observaremos nas partes seguintes deste artigo, está permeado tanto pelo presente vivido pelo escritor, quanto por constituições narrativas e representações da sua personagem Antínoo que, a princípio, vivera provavelmente no século II d.C. Interpretamos, desse modo, na perspectiva da História Cultural, que esse poema é um exemplar importante para os estudos sobre as reapropriações da antiguidade pela arte moderna e sobre as representações das relações homoafetivas no início do século XX.

Junto de uma sucinta investigação material e histórica da fonte em foco, a presente pesquisa visa, de um lado, à luz da hermenêutica filosófica e da historiografia cultural, analisar qual o significado dado por Fernando Pessoa ao, por assim dizer, significante histórico 'Antínoo (personagem), 12 no respectivo poema em que Pessoa reinterpretou-o mediante sua tradição literária. Poema cujo título original em inglês é Antinous e, desde aqui, sempre que o nome for mencionado em inglês o será referindo-se à obra e não à personagem ou pessoa histórica.

${ }^{12}$ Referimo-nos à clássica oposição entre conceito (significado) e imagem acústica (significante) de SAUSSURE, Ferdinand de. Curso de Linguística geral. São Paulo: Cultrix/Edusp, 1969. Contudo, o significante aqui apontado como 'Antínoo' não o é só como termo, mas como personagem, de modo que podemos dizer, analogamente, que nos interessa analisar a personagem-em-si (ou persona) e a personalidade (stricto sensu) de Antínoo no poema de Pessoa.

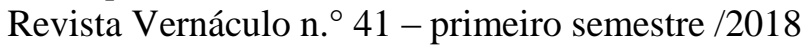

ISSN 2317-4021 
Isso dito, por reinterpretação entendemos dois atos de interpretação sobrepostos, onde uma interpretação ulterior é feita sobre uma interpretação anterior. Ambas, porém, podem ter sido feitas pelo mesmo leitor e/ou autor, mas em tempos distintos. No que se refere ao caso desta pesquisa, trata-se da interpretação de Pessoa sobre: de um lado, uma interpretação já vigente em sua tradição, parcialmente desde as várias esculturas do Renascimento; e, de outro lado, sobre uma interpretação advinda do esteticismo do séc. XIX - notadamente de Oscar Wilde ${ }^{13}$; além disso, uma interpretação de seu próprio poema Antinous desde a edição de 1918 para a de 1921.

Interpretação que pode ser entendida formalmente, à maneira da Lógica, Matemática e Computação, como a atribuição de algum significado aos símbolos de uma dada linguagem (formal ou não) onde tal interpretação especifica: (I) um domínio (ou universo) de discurso não-vazio; (II) o objeto de domínio a que cada termo tem por referência ou denotação; (III) para cada predicado da linguagem, uma propriedade ou relação; (IV) uma ou mais propriedades a que se ligam os sujeitos

${ }^{13}$ Conferir o Prefácio à Segunda Edição de The Picture of Dorian Gray, revisado e publicado por Oscar Wilde em abril de 1891: WILDE, Oscar. Retrato de Dorian Gray. Ed. bilíngue. Trad. de Marcella Furtado. São Paulo: Landmark, 2009, p. 11-12. Por sua vez, na introdução do mesmo livro, lemos: "as bases do Esteticismo foram desenvolvidas principalmente por Walter Pater, professor de Estética da Universidade de Oxford, cuja obra [...] influenciaria toda uma geração de escritores, pintores e artistas, entre eles o próprio Wilde. O movimento defendia o 'belo' como única solução contra tudo o que considerava denegrir a sociedade da época" (WILDE, Oscar. Op. cit., 2009, p. 5). Ver também o poema The Sphinx, de 1894 (Disponível em: <https://ebooks.adelaide.edu.au/w/wilde/oscar/w67p/chapter15.html>. Acessado às 18:16 de 09/04/2017), também de Oscar Wilde, e que também trata de Antínoo e precede a obra aqui analisada de Fernando Pessoa.

Revista Vernáculo n. ${ }^{\circ} 41$ - primeiro semestre $/ 2018$

ISSN 2317-4021 
(ou indivíduos) do discurso; (V) e uma função de valoração que conecta as sentenças proferidas a valores de verdade, falso, indeterminado etc. ${ }^{14}$. Contudo, interessa-nos particularmente a interpretação textual, i.e. a atribuição de algum significado/sentido ao texto (poético ou em prosa) de uma dada língua - e, definida dessa maneira, trata-se notadamente do objeto de estudo da semiótica discursiva ${ }^{15}$ em vez da semântica ${ }^{16}$ meramente em uma palavra ou frase. A tal ponto, como considera Ricoeur em A Metáfora Viva (2005), passa-se da frase ao discurso propriamente dito - i.e. poema, narrativa, discurso filosófico —, deixando o nível estritamente semântico e chegando ao nível hermenêutico. Por conseguinte, e como reconhece Ricoeur, é possível definir uma obra literária - seja ela ficção, ensaio ou poema - como "um discurso que comporta uma parte importante de significações implícitas", embora uma obra literária não seja só isso ${ }^{17}$, e algumas dessas significações implícitas serão aqui investigadas.

Por sua vez, no que diz respeito à função interpretativa, segundo a tradição hermenêutica, entendemo-la pelos fenômenos desde a intersecção efetiva entre o mundo da obra e o mundo do leitor. Com efeito, é por meio dessa interseção que compreendemos justamente o

${ }^{14}$ BLACKBURN, Simon. Dicionário Oxford de filosofia. Rio de Janeiro: Zahar, 1997, p. 207.

${ }^{15}$ DE BARROS, Diana Luz Pessoa. Estudos do discurso. In: FIORIN, José Luiz (org.). Introdução à Linguística: II. Princípios de análise. São Paulo: contexto, 2012, p. 187.

${ }^{16}$ Vide LYONS, John. Linguistique générale: introduction à la linguistique théorique. Trad. De F. Dubois-Charlier et D. Robinson. Paris: Larousse, 1970, pp. 307-325.

${ }^{17}$ Cf. RICOEUR, Paul. A Metáfora Viva. São Paulo: Loyola, 2005, pp. 144-145. Revista Vernáculo n. ${ }^{\circ} 41$ - primeiro semestre /2018 
conceito de fusão de horizontes de Gadamer ${ }^{18}$ diante da impossibilidade de suspensão de pressupostos (pré-conceitos) junto ao conceito heideggeriano de círculo hermenêutico ${ }^{19}$. Portanto, e o que mais nos interessa nesse trabalho, a função interpretativa ${ }^{20}$ é fundamental para compreender, segundo Ricoeur, a passagem ${ }^{21}$ da mímesis I (campo prático pré-figurado) para a mímesis II (configuração do mundo textual) e, por sua $\mathrm{vez}^{22}$, para a mímesis III (re-figuração do campo prático), em suas palavras:

Abrir para fora a noção de composição da intriga e a noção de tempo que lhe é apropriada significa, finalmente, acompanhar o movimento de transcendência pelo qual toda obra de ficção, verbal ou plástica, narrativa ou lírica, projeta para fora de si mesma um mundo que pode ser chamado de mundo da obra. Assim, a epopeia, o drama, o romance

GADAMER, Hans-Georg. Hermenêutica da obra de arte. Trad. de Marco Casanova. São Paulo: Martins Fontes, 2010, pp. X-XI.

${ }^{19}$ GADAMER, Hans-Georg. Verdade e Método I: traços fundamentais de uma hermenêutica filosófica. Rio de Janeiro: Vozes, 2013, pp. 354-385.

${ }^{20}$ Entendemos aqui "função da interpretação" ou "função interpretativa" enquanto uma função dinâmica que pode variar conforme a mímesis em questão. No caso da passagem da mímesis I para a II, trata-se de uma função de $A$ - i.e. o conjunto de elementos do mundo - e $B$ - i.e. o conjunto de elementos da obra -, onde, porém, nem todos os elementos do mundo (de $A$ ') estão configurados de alguma forma na obra $(B)$, bem como o mesmo elemento mundano pode estar, devido ao autor, ligado a mais de um elemento na obra, portanto. Já no caso da passagem da mímesis II para a III, temos um novo mundo $(A$ '), transformado pela re-figuração feita após a leitura e interpretação através da obra $(B)$.

${ }^{21}$ HEITICH, Paulo Ricardo. Paul Ricoeur: A Tríplice Mímese. In: Problemas filosóficos da contemporaneidade. ANAIS - IX SEMANA ACADÊMICA DE FILOSOFIA UNICENTRO, 2010, pp. 1-2.

${ }^{22}$ RICOEUR, Paul. Tempo e Narrativa: vol. 2. A configuração do tempo na narrativa de ficção. Trad. de Márcia Valéria Martinez de Aguiar e revisão de Claudia Berliner. São Paulo: Martins Fontes, 2012, p. 10.

Revista Vernáculo n. ${ }^{\circ} 41$ - primeiro semestre /2018

ISSN $2317-4021$ 
projetam, ao modo da ficção, maneiras de habitar o mundo que ficam na expectativa de uma retomada pela leitura, capaz por sua vez de fornecer um espaço de confrontação entre o mundo do texto e o mundo do leitor. Os problemas de refiguração próprios à mímesis III só começam, estritamente falando, nessa e por essa confrontação. ${ }^{23}$

\section{Da fonte de análise}

Fernando Pessoa nasceu em 1888 na cidade de Lisboa, Portugal, e foi poeta, escritor, crítico literário, entre outras ocupações, enquadrando-se no perfil do que Cunha (2008) define como homens de letras. Estes homens geralmente atuaram em diversas áreas de conhecimentos, entre as quais: a medicina, a vida militar, a engenharia e o direito, ao mesmo tempo em que ocupavam espaços públicos fundamentais em campos que no país estavam em vias de consolidação, tais quais a literatura e a história. Educado na África do Sul, o poeta possuiu desde jovem uma grande familiaridade não apenas com a língua portuguesa, mas principalmente com a língua inglesa, com a qual se relacionou constantemente durante sua vida, fosse na escrita de seus textos e poemas, ou na atividade de tradução de textos de autores como Shakespeare e Edgar Allan Poe para o português.

Pessoa publicou durante as décadas de 1910 e 1920, especialmente, uma série de poemas e sonetos em língua inglesa no formato de folhetos. Entre esses, o soneto "Antinous", foco deste artigo

${ }^{23}$ RICOEUR, Paul. Tempo e Narrativa: vol. 2. A configuração do tempo na narrativa de ficção. Trad. de Márcia Valéria Martinez de Aguiar e revisão de Claudia Berliner. São Paulo: Martins Fontes, 2012, p. 9.

Revista Vernáculo n. ${ }^{\circ} 41$ - primeiro semestre /2018

ISSN 2317-4021 
e publicado pela primeira vez em 1918. Após tal publicação, o escrito passou cerca de quatro anos nesse formato, até que foi incluído em uma coletânea de textos de sua autoria, em 1922, intitulada English Poems III e English Poems III. Contudo, a chegada do poema ao Brasil só veio a ocorrer décadas após sua primeira publicação, já no período pós-morte de Pessoa. Pouco conhecido entre os pesquisadores brasileiros, possivelmente pela própria língua na qual foi publicado primeiramente (SENA, 1965), o soneto só veio a ser traduzido pela primeira vez no país no final da década de 1950, através do Clube de Poesia de São Paulo, que editou uma versão bilíngue de seus textos, contendo 14 dos 35 sonetos publicados no English Poems. De acordo com a apresentação de "21 dos '35 sonnets' de Fernando Pessoa”, publicada em 1965, o tradutor afirma que, ao chegar no Brasil, possuía a obrigação contratual de fazer uma edição bilíngue das "obras completas" de Pessoa para a Ática Editôra, editora oficial do autor em solo nacional.

Já no nome que intitula o poema, chegamos a Antínoo (Antinous, em inglês e na versão latinizada), do grego Avtívoos, nome dado provavelmente em referência ao personagem de mesmo nome que aparece na Odisseia de Homero, onde Antínoo é um dos dois pretendentes que disputam a mão de Penélope e é descrito frequentemente como violento e excessivamente confiante $^{24}$. Mas a pessoa histórica a que Pessoa se refere é muito posterior a Homero.

${ }^{24}$ Cf. HOMERO. Odisseia, Canto I, vv. 364-374 e vv. 384-393; Canto IV, vv. 627631; e Canto XVII, vv. 453-466.

Revista Vernáculo n. ${ }^{\circ} 41$ - primeiro semestre /2018

ISSN 2317-4021 
Pelas fontes antigas a seu respeito - notadamente Clemente de Alexandria, no Livro IV da Exortação aos Gregos (Protreptikos pros Ellenas), e a Descrição da Grécia (Periegesis Hellados) ${ }^{25}$ de Pausânias - Antínoo teria nascido em Claudiópolis, na província romana da Bitínia, em 27 de novembro (Inscriptiones Latinae Selectae, 7212) entre 111 e 115 d. C. ${ }^{26}$, sendo que a obra de Pausânias ${ }^{27}$ ainda sugere que Antínoo morreu durante sua vida ("I never saw him in the flesh, but I have seen images and pictures of him ${ }^{28}$ ). Com efeito, Antínoo teria morrido em outubro de 130 d. C. ${ }^{29}$ no Rio Nilo ${ }^{30}$, junto a Besa — onde ao Sul, posteriormente, foi fundada pelo imperador Adriano em sua

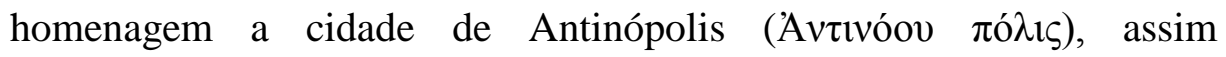
referenciada por Pausânias ${ }^{31}$.

É possível, pois, que o então imperador romano Públio Élio Trajano Adriano - apelidado de Gréculo ("pequeno grego"), devido a sua apreciação da cultura grega — tenha conhecido Antínoo numa

${ }^{25}$ Obra essa que teria sido escrita entre 160 e 176 d. C., haja vista que a obra menciona a sucessão de Antonino Pio por Marco Aurélio (o segundo Antonino) em 161 d.C. (Livro VIII, cap. 43, §6), mas não a sucessão de Marco Aurélio em 180. Obra escrita, pois, décadas após a morte de Antínoo.

${ }^{26}$ BACKE, Annika. Antinoos: Geliebter und Gott. Berlin: Staatliche Museen zu Berlin, Stiftung Preußischer Kulturbesitz, 2005.

${ }^{27}$ Vide a Descrição da Grécia, Livro VIII [Arcádia], cap. 9, §7.

${ }^{28}$ Ver bibliografia para conferir a versão traduzida a que cá nos referimos.

29 Seguramente ocorreu poucos dias antes de 30 de outubro de 130 d. C., quando o então imperador Adriano fundou a cidade de Antinópolis, possivelmente no dia 22 (devido ao Festival do Nilo) ou mais certamente no dia 24 (aniversário da morte de Osíris). Cf. LAMBERT, Royston. Beloved and God: The Story of Hadrian and Antinous. George Weidenfeld \& Nicolson, 1984, p. 19.

${ }^{30}$ Pessoa no poema Antinous mostra conhecimento disso: "Now the Nile gave him up, the eternal Nile".

${ }^{31}$ LAMBERT, Op. cit., p. 19.

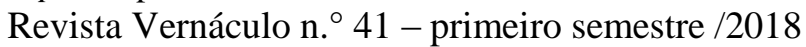

ISSN 2317-4021 
visita à Bitínia e o levado. Desse modo, Antínoo, jovem e belo, tornouse, segundo Pausânias ${ }^{32}$, o "favorito" de Adriano, provavelmente como seu catamita $^{33}$ - i.e. um jovem companheiro sexualmente passivo de um homem mais velho em uma relação de pederastia ${ }^{34}$. Haja vista que o imperador era, no momento, trinta e quatro anos mais velho que seu amante e que Clemente de Alexandria (Protreptikos pros Ellenas, IV) compara a relação deles com a de Zeus e Ganímedes ${ }^{35}$ - príncipe de Troia (supostamente o mais belo entre os mortais) a que Zeus se apaixonou e levou-o ao Olimpo para ser seu copeiro no lugar de $\mathrm{Hebe}^{36}$.

Convém lembrar que o que se chama de pederastia ocorreu, segundo Fisher $^{37}$, durante toda a história antiga grega, embora "institucionalizada", por assim dizer, a partir do séc. VII a. C., pari passu ao fato de que o casamento era proibido ou fortemente desencorajado para os homens com menos de 30 anos. Todavia havia diferentes visões, segundo não só a temporalidade, mas a área geográfica, que variavam desde a aceitação total até a recusa absoluta

${ }^{32}$ LAMBERT, Op. cit., p. 19.

${ }^{33}$ CARITÓN DE AFRODISIAS/ JENOFONTE DE ÉFESO. Quéreas y Calírroe / Efesíacas. Fragmentos novelescos. Madrid: Gredos, 1979, p. 236, nota 6 de Julia Mendoza.

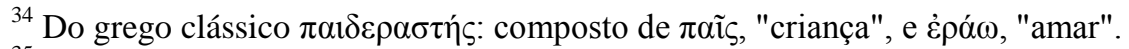

${ }^{35}$ Comparação também lembrada por Pessoa em Antinous: "And in one mound of death its remnant spill!/ But, by sweet Ganymede, that Jove found worth" e também, referindo-se a Zeus após a morte de Antínoo: "Maybe thy better Ganymede thou feel'st/ That he should be, and out of jealous carel From Hadrian's arms to thine his beauty steal's".

${ }^{36}$ COMMELIN, P. Mitologia Grega e Romana. São Paulo: Martins Fontes, 1993, pp. 75-77.

${ }^{37}$ Refiro-me a FISHER, Nick. Aeschines: Against Timarchos. Oxford University Press, 2001, p. 27.

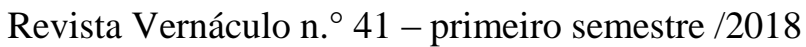

ISSN 2317-4021 
da prática, como atesta Platão ${ }^{38}$, ao mesmo tempo que chega a reconhecê-la como um elemento de distinção entre a cultura helênica e

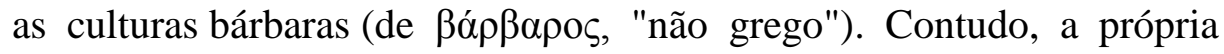
natureza do relacionamento em questão variava entre o estrito fascínio erótico e estético até a prática do ato sexual como única razão de ser de tal aproximação ${ }^{39}$, podendo estar inserida na educação do rapaz, que por vezes aprendia algum ofício em que seu "mestre" (pedagogicamente falando) era versado, e, assim, o próprio catamita (e/ou sua família) almejava ascensão social - queira pela aproximação per si com o homem mais velho prestigiado, queira pela técnica em questão obtida pelo ensino.

Outrossim, a retratação artística da pederastia e da efebia, por sua vez, é comum já na pintura ${ }^{40}$ e literatura ${ }^{41}$ antigas da Grécia. Entretanto, queira no final da antiguidade (como relata Pausânias, na citação supra), queira em todo o período moderno (principalmente em

${ }^{38}$ Ver diálogo Banquete, de $181^{\mathrm{d}}$ a $182^{\mathrm{e}}$.

${ }^{39}$ FISHER, Op. cit., 2001. p. 26.

${ }^{40}$ Veja-se, por exemplo, a pintura em ânfora ática (c. 540 a. C.) em que o erastas (amante) toca o queixo e genitália do eromenos (amado). Atualmente nas Coleções Estatais de Antiguidades (Staatliche Antikensammlungen). Alemanha, Munique. Beazley, $A B V, \quad 315, \quad 3$, inv. 1468. Disponível em: <https://pt.wikipedia.org/wiki/Pederastia\#/media/File:Erastes eromenos_Staatliche_A ntikensammlungen 1468.jpg>, acessado em 20/01/2017 às 11:54.

${ }^{41}$ Vide, exemplarmente, um estudo já clássico de Vidal-Naquet sobre a tragédia Filoctetes de Sófocles, traduzido por Maria da Conceição M. Cavalcante em VIDALNAQUET, Pierre; VERNANT, Jean-Pierre. Trad. por Maria da Conceição M. Cavalcante. Mito e Tragédia na Grécia Clássica. São Paulo: Perspectiva, 1999, pp. $125-145$.

Revista Vernáculo n. ${ }^{\circ} 41$ - primeiro semestre /2018

ISSN 2317-4021 
numerosas esculturas e na literatura ${ }^{42}$ ), nenhuma outra ocorrência histórica dessa natureza no Ocidente é mais célebre que a da relação de Adriano e Antínoo, particularmente após a morte deste, tendo capturado a atenção de numerosos artistas. Contudo, a morte de Antínoo até hoje não está bem esclarecida. Dificilmente o jovem foi assassinado por motivos políticos, pois seu status não representava qualquer ameaça ao imperador. Por um lado, Antínoo pode ter se suicidado devido a estar com cerca de 20 anos, quando seu encanto juvenil já começava a não ser mais o mesmo. Por outro, pode ser o caso de Antínoo ter se oferecido em sacrifício - numa época em que Adriano estava com problemas de saúde, havia revoltas no Império e fome e seca no Egito - haja vista ainda que Adriano e Antínoo tinham sido iniciados nos mistérios de Elêusis ${ }^{43}$, sendo provável que as suas vidas tenham tomado um caráter mais místico; tal explicação, aliás, também ganha plausibilidade pelo fato de Antínoo, após a morte, ter sido deificado e vinculado à figura de Osíris ${ }^{44}$. Seja como for, segundo as fontes da

${ }^{42}$ Na poesia; notadamente Oscar Wilde e Fernando Pessoa nos respectivos poemas The Sphinx e Antinous, ambos em inglês, e provavelmente o segundo com influência do primeiro; e na prosa, vale mencionar, mais recentemente, a obra "Memórias de Adriano" (Mémoires d'Hadrien), de 1951, escrita por Marguerite Yourcenar (YOURCENAR, Marguerite. Mémoires d'Hadrien. Paris: Plon, 1951), primeira mulher eleita à Académie française. Ademais, citando a romancista e estudiosa britânica Sarah Waters, a figura de Antínoo "reappears with striking regularity in the newly self -identified homosexual literature of the late Victorian period" (WATERS, Sarah. 'The Most Famous Fairy in History': Antinous and Homosexual Fan-tasy. Journal of the History of Sexuality, 6:2, 1995, p. 195).

${ }^{43}$ HOFMANN, Albert; GORDON, Wasson, R.; RUCK, Carl. El camino a Eleusis: una solución al enigma de los misterios. México: Fondo de Cultura Económica, 1993.

${ }^{44}$ Ademais, uma evidência material disso é o busto de Antínoo como Osíris (com restauração moderna), atualmente no Louvre, primeiro andar, sala 5, Ma 433 (MR 16),

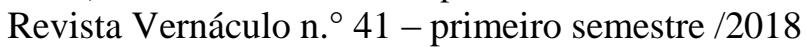


época, após a sua morte Adriano teria "chorado como uma mulher". Por todo o Império Romano foram erguidas numerosas estátuas de Antínoo e na parte oriental do Império levantaram-se templos dedicados ao jovem, além da cidade de Antinópolis, que já mencionamos. Ademais, foi dado o nome Antínoo a uma estrela (lembrando a associação da constelação de Aquário com o Ganímedes da mitologia) e o imperador escreveu um epitáfio dedicado ao jovem, gravando-o no chamado "obelisco de Antínoo", que se encontra hoje nos Jardins de Pincio, em Roma.

\section{Analítica}

O poema Antinous (publicado duas vezes: 1918 e $1921^{45}$ ) faz parte daquilo que o próprio Fernando Pessoa denominou "ciclo imperial", relacionado à (1) Grécia — principalmente por esse poema, o qual o poeta considerava "grego quanto ao sentimento", mas romano

disponível online em: 〈https://commons.wikimedia.org/wiki/File:Antinousosiris.JPG > (acessado às 23 horas do dia 19 de dezembro de 2016). Ver também Clemente de Alexandria, Protreptikos pros Ellenas, IV.

${ }^{45}$ A primeira versão foi qualificada pelo autor como "an early and very imperfect draft", de modo que a versão revista deveria tratar de "anular e substituir " ("annul and supercede") (DIONÍSIO, João. Introdução. Poemas Ingleses. Antinous, Inscriptions, Epithalamium, 35Sonnets. Edição Crítica de Fernando Pessoa, Série Maior, Vol. V, tomo 1. Ed. João Dionísio. Lisboa: IN-CM, 1993, p. 26); e outros comentários de Pessoa incluem referências ao processo de "reconstruir e aperfeiçoar" (Idem, p. 29) tal poema. Não obstante a sua intenção, reiteradamente declarada, de considerar válida apenas a versão posterior do poema, Pessoa mostrava-se aberto a disponibilizar a edição de 1918 a quem a quisesse examinar, nomeadamente a João Gaspar Simões em 1930 e a Alberto de Serpa em1933. Sendo que, neste último caso, a oferta ainda incluiu o encorajamento a uma leitura comparada das duas versões: "Diga-me se quere esse outro folheto; talvez, até, lhe interesse comparar uma versão com a outra, para ver a technica psychica a que as alterações obedecem" (Ibidem, pp. 31-32).

Revista Vernáculo n. ${ }^{\circ} 41$ - primeiro semestre $/ 2018$

ISSN $2317-4021$ 
quanto ao dado histórico - , (2) a Roma - pelo Epithalamium - e (3) à Cristandade - tendo em vista Prayer to a Woman' body-, Império Moderno - relativo ao Pan-Eros - e Quinto Império - Anteros -; todos em língua inglesa.

Sendo que o poema Antinous, junto com Epithalamium, achase num conjunto poético que Pessoa considerou "obsceno" — sendo que, em Epithalamium, esta dimensão obscena para ele ainda é "mais direta e bestial." No que diz respeito à publicação, há de se sublinhar o “Apêndice" à edição da Obra poética de Fernando Pessoa ${ }^{46}$; particularmente referimo-nos à seção "Notas e Variantes" dos "Poemas Ingleses". Por conseguinte, numa observação do próprio Pessoa ${ }^{47}$, com respeito à escrita dos poemas Antinous e Epithalamium, dirigida em carta a Cortes Rodrigues, em 4 de setembro de 1916, lemos: "vai sair Orfeu 3. É aí que, no fim do número, publico dois poemas ingleses meus, muito indecentes, e, portanto, impublicáveis em Inglaterra".

Contudo, uma compilação completa de suas obras em inglês há desde 1922: English Poems I-II e III. E, fora do julgamento crítico de autores de língua portuguesa, a poesia pessoana escrita em inglês foi bem recebida ${ }^{48}$. No entanto, tendo Pessoa ${ }^{49}$ os enviado à Inglaterra, a

${ }^{46}$ Volume único, com organização, introdução e notas de Maria Aliete Galhoz. Rio de Janeiro: Editora Nova Aguilar S.A., 1977, p. 809.

${ }^{47}$ PESSOA, Fernando. Obra poética. Organização, tradução e notas de Maria Aliete Galhoz. Rio de Janeiro: Editora Nova Aguilar S.A., 1977, p. 810.

${ }^{48}$ Cf. LOZADA, Jorge Alberto Uribe. Um Drama Da Crítica: Oscar Wilde, Walter Pater e Matthew Arnold, Lidos por Fernando Pessoa. Doutoramento em Estudos da Literatura e da Cultura (Teoria da Literatura). Lisboa: Universidade de Lisboa, 2014, pp. 193-195.

Revista Vernáculo n. ${ }^{\circ} 41$ - primeiro semestre /2018

ISSN 2317-4021 
dois jornais ingleses (The Times e Glasgow Herald, em número publicado com igual data, 19 de setembro de 1918), na parte destinada à crítica literária, fizeram-lhe elogios, chamando a atenção para o domínio perfeito dos versos em inglês, por eles chamados quase "isabelinos", e acentuando neles a "composição formal" — sobretudo em relação aos sonetos, feitos à maneira shakespeariana, com três quadras seguidas de um dístico, tudo em versos decassílabos, o que não deixa suspeitas desde o primeiro soneto, que transcrevo abaixo (de rimas $a b a b, c d c d, e f e f, g g$ ) segundo a compilação já mencionada:

\section{Sonnet 1:}

WHETHER WE WRITE or speak or do but look We e are ever unapparent. What we are Cannot be transfused into word or book.

Our soul from us is infiniteley far.

However much we give our thoughts the will

To be oor soul and gesture it abroad,

Our hearts are incommunicable still.

In what we show ourselves we are ignored.

The abyss from soul to soul cannot be bridged.

By any skill of thoughts or trick of seeming.

Unto our very selves we are abridged

When we would utter to our thooughts our being.

We are ur dreams of ourselves suls by gleams, And each to each other drems of others' dreams.

Outrossim, considerando a Nota Preliminar de Pessoa - que se trata de uma carta a Gaspar Simões, datada de 18 de novembro de 1910 -, Antinous é mesmo uma poesia menos sintática e

${ }^{49}$ PESSOA, Op. cit., 1977, p. 810.

Revista Vernáculo n. ${ }^{\circ} 41$ - primeiro semestre /2018

ISSN 2317-4021 
estilisticamente difícil que os 35 sonnets. Ademais, Antinous, como também o Ephitalamium, compõe o "círculo do fenômeno amoroso" não completado pelo autor - por meio do qual Pessoa procura vivenciar a obscenidade que todo humano possuiria em maior ou menor grau, aqui, particularmente pela tematização do amor. Pessoa ainda sustentava que, para compor esse tipo de poema, seria necessário empregar recursos expressionais "simples" a fim de comunicar o componente da lascívia de maneira intensa, uma vez que - reconhecia ele - , na construção de poemas de tal natureza, iria se deparar com o que chamou de "certos estorvos para alguns processos mentais superiores" (PESSOA, 18 de Novembro de 1930), assim justificando os versos livres e uma diferença formal quanto aos 35 sonnets.

No que tange às alterações textuais entre a publicação de 1918 para a de 1921, já mencionadas no início do presente tópico, ressaltamos, como já o fez Anna Klobucka ${ }^{50}$, que

claro que a maior parte das revisões que Pessoa introduziu no texto de "Antinous" obedece a um esforço manifesto de aperfeiçoamento estético, como se pode constatar facilmente já à base do primeiro verso do poema (1918: "It rained outside right into Hadrian's soul"; 1921: "The rain outside was cold in Hadrian's soul"). Mas a expressão "technica psychica", usada por Pessoa para caracterizar a intencionalidade que determinou o processo de

50 KLOBUCKA, Anna M. Fernando Pessoa ativista queer: Uma releitura do 'Antinous'. University of Massachusetts Dartmouth. III CONGRESSO INTERNACIONAL FERNANDO PESSOA, Lisboa, 28-30 de novembro de 2013, p. 2. Disponível em: <https://umassd.academia.edu/AnnaMKlobucka> (acessado em 05 de Janeiro de 2017 às 11:59).

Revista Vernáculo n. ${ }^{\circ} 41$ - primeiro semestre /2018

ISSN 2317-4021 
revisão, não terá um significado circunscrevível aos valores puramente estilísticos. Como já sugeriu George Monteiro no seu ensaio sobre "Antinous" e como comprova uma comparação mais exaustiva das duas versões, Pessoa foi meticuloso e sistemático em retirar do texto todas as expressões associáveis com um juízo de valor negativo sobre a homossexualidade.

Com efeito, a autora ${ }^{51}$ exemplifica, sem pretender exaustão, sua tese pelo seguinte trecho:

Edição de 1918:

soiled art

glory of a wrong lust

all his vices' art

of love's art most unholy

the memories of his vice

new crimes of fancy

beauty \& vice and lust
Edição de 1921:

live art

complete regency of lust

all his arts and toys

that makes love captive wholly

the memories of his love

new turns of toying

beauty that doth make a lust

Desse modo, observa-se que o poema, no que toca a sua primeira versão, insere-se não só no cânone emergente britânico por sua temática homoafetiva como também a sua linguagem adere igualmente aos padrões vigentes do discurso sobre a homossexualidade. ${ }^{52} \mathrm{Um}$ dos marcos mais eloquentes desta adesão é, pois, o uso do termo "vice"

${ }^{51}$ KLOBUCKA, Op. cit., p. 3.

${ }^{52}$ É necessário destacarmos que neste período a homossexualidade, na jurisprudência inglesa, não era considerada como mero vício, mas sim um crime de indecência.

Revista Vernáculo n. ${ }^{\circ} 41$ - primeiro semestre $/ 2018$

ISSN 2317-4021 
(vício) que, segundo Graham Robb ${ }^{53}$, tratava-se da palavra mais comum em títulos de romances com temática homoafetiva na última década do século XIX e nos primeiros anos do século XX. Ora, tal termo é repetido seis vezes na primeira edição de Antinous - entre eles, a passagem citada acima —, e na versão de 1921 já não aparece uma única vez ${ }^{54}$.

Com efeito, a primeira edição (de 1918) de Antinous caracteriza-se por uma contradição entre o postulado de Pessoa e seu léxico ${ }^{55}$. Postulado e léxico esses que passariam a se harmonizar na edição de 1921. Ora, como já ressaltou Roman Jakobson ${ }^{56}$, a obra de Pessoa é essencialmente dramática ${ }^{57}$ e "[a]s supostas incoerências e contradições nos escritos poéticos teóricos de Pessoa refletem em realidade o 'diálogo interno' do autor”. Com efeito, o postulado central de Pessoa em Antinous, ao que parece, refere-se ao projeto da

${ }^{53}$ ROBB, Graham. Strangers: Homosexual Love in the Nineteenth Century. New York \& London: W. W. Norton, 2003, p. 203.

${ }^{54}$ Destaca-se ainda notavelmente a mudança do seguinte verso: (1918) "Some shall say all our love was vice and crimes" [Dirão que nosso amor era vício e crimes]; (1921) "Some shall say all our love was but our crimes" [Dirão que nosso amor só era os nossos crimes]. A tradução da edição de 1921 que seguimos desde aqui é a tradução clássica de Jorge de Sena, em Poemas ingleses, na edição da Ática de 1974.

${ }^{55}$ Seguindo Anna Klobucka (Op. cit., p. 4).

56 JAKOBSON, Roman. Os oxímoros dialéticos de Fernando Pessoa. Trad. de Haroldo de Campos. In: SAUSSURE; JAKOBSON; HJELMSLEV; CHOMSKY. Textos selecionados. Coleção "Os Pensadores". São Paulo: Abril Cultural, 1978, p. 122.

57 Aludindo ao que o próprio poeta português considera sobre sua obra: "O ponto central da minha personalidade como artista é que sou um poeta dramático; tenho continuamente, em tudo quanto escrevo, a exaltação íntima do poeta e a despersonalização do dramaturgo" (PESSOA, Fernando. Páginas de Doutrina Estética. Lisboa, 1946, p. 226-227).

Revista Vernáculo n. ${ }^{\circ} 41$ - primeiro semestre $/ 2018$

ISSN 2317-4021 
personagem Adriano de erguer uma estátua às futuras gerações ${ }^{58}$ para, mais do que mostrar a beleza de seu amado (erómenos) Antínoo, impressioná-las e dar raiva aos futuros corações por não serem contemporâneos àquele amor que constitui uma vitória romana ${ }^{59}$ ou uma vitória grega (a Grecian victory) - para aludir ao título primário concebido por Pessoa ao poema que, por sua vez, lembra a expressão inglesa greek love para designar "amor homossexual", sobretudo masculino.

Dito isso, a revisão de "Grecian victory" de 1918 para "Roman victory" de 1921 acentua o contraste com o poema seguinte do "ciclo amoroso", a saber, o poema Ephitalamium, sendo que esse, por sua vez, ressalta a "bestialidade romana" uma conotação mais positiva ao relacionamento de Adriano e Antínoo e condena julgamentos negativos que viriam no futuro acerca de tal amor, talvez por não compreenderem a beleza nele, pois a todo momento o poema trabalha com essa associação. Destacamos - seja para a relação amor-beleza, seja para a mensagem de Adriano ao futuro - o seguinte trecho:

Some will say all our love was but our crimes;

${ }^{58}$ Pessoa retrata esse fato no Antinous em alguns versos da fala de Adriano: "I shall build thee a statue that will be /To the continued future evidence /Of my love and thy beauty and the sense /That beauty giveth of divinity". Apesar de se referir a "a statue", provavelmente simboliza o vasto legado deixado à posteridade que foi dedicado ao amado, tal como comentamos no tópico anterior sobre Antínoo na antiguidade.

59 "Eternal, like a Roman victory, /In every heart the future will give rages /Of not being our love's contemporary".

${ }^{60}$ DIONÍSIO, Op. cit., 1993, p. 30.

Revista Vernáculo n. ${ }^{\circ} 41$ - primeiro semestre /2018

ISSN 2317-4021 
[Dirão alguns que nosso amor era só crimes;]

Others against our names the knives will whet

[Outros em nossos nomes afiarão facas]

Of their glad hate of beauty's beauty, and make

[Do ódio contente ao belo da Beleza, e hão-de]

Our names a base of heap whereon to rake

[Fazer de nossos nomes sítio onde gravar]

The names of all our brothers with quick scorn.

[Os nomes de irmãos nossos com veloz desprezo]

Yet will our presence, like eternal Morn,

[Mas a nossa presença, com Áurora eterna]

Ever return at Beauty's hour, and shine

[Sempre com a beleza há-de voltar, brilhando]

Desse modo, "Pessoa formula um contradiscurso de resistência antihomofóbica, discurso que em breve será transferido para os textos que irá escrever em defesa da poesia homoerótica de António Botto",61, tendo em vista a publicação da primeira edição das Canções de António Botto em 1921 (precedida da versão intitulada Canções do Sul em 1920) e, além disso, a fundação e primeiras publicações da empresa editorial Olisipo, dentre as quais, nos finais de 1921, A invenção do dia claro de Almada Negreiros e os English Poems I-II e III de Fernando Pessoa, seguidos,

logo no início de 1922, da segunda edição das Canções de Botto; e, um ano mais tarde, o lançamento pela editora de Pessoa de Sodoma divinizada de Raul Leal, evento que desencadeia a violência do chamado episódio de "Literatura de Sodoma" em que os livros de Botto e Leal, publicados por Pessoa, se encontram envolvidos juntamente com o volume Decadência de Judith

${ }^{61}$ KLOBUCKA, Op. cit., p. 9.

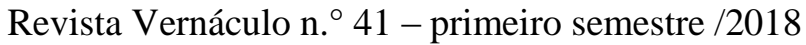

ISSN 2317-4021 
Teixeira e que dá origem a dois panfletos de Pessoa, Aviso por causa da moral, assinado por Álvaro de Campos, e Sobre um manifesto de estudantes, em seu próprio nome. ${ }^{62}$

Ora, tendo em vista, de um lado, a produção editorial de Olisipo e, de outro, o conhecimento de Pessoa da literatura britânica e do julgamento de Oscar Wilde de 1895, não é difícil concordar com Robert Howes ao ver em Pessoa "effectively a gay imprint" $"$. Contudo, tal "gay imprint" aparece em Antinous menos pela comemoração em si de um fenômeno passado e mais pelo ensinamento estético-sentimental de Adriano às gerações futuras. "A exaltação amorosa [escassamente desenvolvida nas demais obras de Pessoa] da personagem Adriano assume a característica de experiência que vai conduzir à visão de um "mais além", que se oculta sob a aparência imediata"64.

Assim, Pessoa encontra-se primeiramente entre os artistas do final do XIX e início do XX que mostram um relacionamento homossexual belo onde a personagem ou obra em si não se compromete diretamente com a moral — para aludir à conhecida afirmação de Oscar Wilde: "There is no such thing as a moral or an immoral book. Books are well written, or badly written. That is all ${ }^{365}$ — concedendo maior liberdade ao artista na medida em que se abstém de julgar ou retratar o

${ }^{62}$ KLOBUCKA, Op. cit., p. 9.

${ }^{63}$ HOWES, Robert. Portugal. In: Gay Histories and Cultures: An Encyclopedia. Vol. 2. Ed. George Haggerty. New York: Garland, 2000, p. 705.

${ }^{64}$ PESSOA, Fernando. Obra poética. Rio de Janeiro, Aguillar, 1974, p. 606; ver também MOISÉS, Carlos Felipe. O Poema e As Máscaras: introdução à poesia de Fernando Pessoa. Florianópolis: Letras contemporâneas, 1999, p. 81.

${ }^{65}$ WILDE, Op. cit., 2009, p. 1.

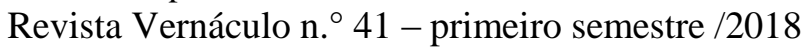

ISSN 2317-4021 
bem ou o mal —, claramente separando a estética da moral. No entanto, pela segunda edição, o poeta português conjuga a beleza desse relacionamento abstraindo-o dos vícios então associados, mas o faz para um tipo de relação específica. A saber, uma relação erastés-erómenos (amante-amado) onde a maioria das metáforas voltam-se para a beleza e a personalidade erótica de Antínoo, o erómenos (amado) de Adriano. Em The Fragility of Goodness, Martha Nussbaum define o ideal de erómenos como:

a beautiful creature without pressing needs of his own. He is aware of his attractiveness, but selfabsorbed in his relationship with those who desire him. He will smile sweetly at the admiring lover; he will show appreciation for the other's friendship, advice, and assistance. He will allow the lover to greet him by touching, affectionately, his genitals and his face, while he looks, himself, demurely at the ground. ... The inner experience of an eromenos would be characterized, we may imagine, by a feeling of proud self-sufficiency. Though the object of importunate solicitation, he is himself not in need of anything beyond himself. He is unwilling to let himself be explored by the other's needy curiosity, and he has, himself, little curiosity about the other. He is something like a god, or the statue of a god. ${ }^{66}$

Semelhantemente Pessoa personifica esse ideal em Antínoo, ressaltando-lhe delicadeza, brancura ${ }^{67}$, volúpia ${ }^{68}$ e "qualidades

${ }^{66}$ NUSSBAUM, Martha. The Fragility of Goodness. Cambridge University Press, 2001, p. 188.

${ }^{67}$ A palavra white aparece explicitamente 4 vezes no poema para caracterizar o corpo de Antínoo, seja para aproximá-lo da semiosfera da morte pelo sentido de frio-gelo, Revista Vernáculo n. ${ }^{\circ} 41$ - primeiro semestre /2018

ISSN 2317-4021 
femininas", mas, ao mesmo tempo, associando-o à escultura ${ }^{69}$ e aos deuses, como na citação acima. Tais associações são perceptíveis, por exemplo, nos seguintes versos:
O eyes half-diffidently bold!
O bare female male-body such
As a god's likeness to humanity
$[\ldots]$
Of his white body is forever cold.
[...]
The god is dead whose cult was to be kissed!
[...]
Take all the female loveliness of earth
[...]
The friendlier love that fills the other's dearth,
The clod of female embraces resolve
To dust, $O$ father of the gods, but spare
This boy and his white body and golden hair!
[...]
He was a kitten playing with lust, playing

Vale lembrar, no que se refere à historicidade das adjetivações apontadas acima, que a ligação anacrônica mais evidente com a antiguidade - seja de Antínoo, seja dos erómenoi ${ }^{70}$ históricos ou mitológicos — talvez seja a do "racialismo" ligado sua criação à juventude, divindade e pureza, pois disso não há um paralelo seguro na

como na primeira aparição do termo, seja aproximando-a do conceito de uma beleza pura ("juventude", "divindade", "pureza") nas três outras passagens.

${ }^{68}$ Só a palavra "lust" aparece 19 vezes no poema, e as metáforas a seu respeito são ainda mais numerosas.

${ }^{69}$ Sendo que as 9 aparições de "statue" no poema estão todas associadas à imortalidade e/ou à memória - queira da beleza de Antínoo, queira do sentimento de Adriano.

${ }^{70}$ Plural de erómenos.

Revista Vernáculo n. ${ }^{\circ} 41$ - primeiro semestre /2018

ISSN 2317-4021 
Grécia Antiga, diferente das "qualificações femininas" postas por Pessoa ao garoto, pois já eram razoavelmente comuns desde a Grécia arcaica, como em Homero, quando "Odisseu chora como uma mulher" ${ }^{, 71}$ por Aquiles, ainda que, por outro lado, não haja segurança quanto ao Antínoo-histórico ter traços efeminados ${ }^{72}$. Todavia, e mesmo abstraindo a sintaxe e estilística formal do poema, um exame raso dos significados implícitos - que caracterizam semanticamente uma obra literária, como dissemos no primeiro tópico - facilmente delega o período de composição da obra, sem, no entanto, deixar de marcar uma transição importante na estética homoafetiva moderna. Com efeito, a partir da diferença entre a edição de 1918 e a de 1921, Pessoa parece reinterpretar não apenas sua tradição, mas o seu próprio pensamento.

Em suma, o "uso do passado" ou a reapropriação histórica de Pessoa, em termos hermenêuticos, por um lado, é, em ambas edições, marcada não só pelas personagens (via influência do poema de Oscar Wilde, sobretudo), mas pelas interpretações desde o início da modernidade que desconheciam o uso das cores nas esculturas gregas ${ }^{73}$ e ligavam à arte clássica grega o branco-límpido, e destacavam a

${ }^{71} \mathrm{Na}$ Odisseia, Odisseu chora como a mulher que grita, com lágrimas exatamente tão

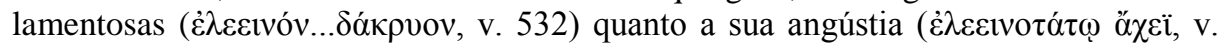

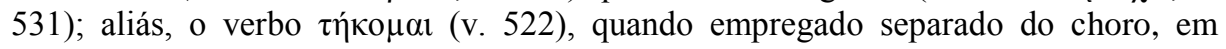
Homero, refere-se apenas a mulheres.

${ }^{72}$ Há várias menções a "traços efeminados" e "andróginos" na Grécia Antiga; entre os mais conhecidos estão alguns comentários de Heródoto (ver respectivamente Histórias, Clio, 105; e Melpomene, 67).

${ }^{73}$ PANZANELLI, Roberta; SCHMIDT, Eike; LAPATIN, Kenneth (eds.). The Color of Life: Polychromy in Sculpture from Antiquity to the Present. Los Angeles: Getty Research Institute, 2008.

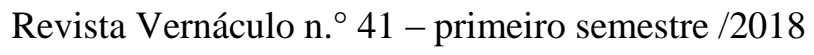

ISSN 2317-4021 
escultura como a principal arte do "espírito da época"74, como tivemos oportunidade de referenciar no poema. Porém, por outro lado, distingue-se na primeira e na segunda edição a apropriação histórica do fenômeno amoroso antigo: na primeira, é algo deveras obsceno; na segunda edição, é uma relação notadamente romantizada (agora, no sentido positivo), com um final enriquecidamente trágico junto a traços morais (de indicar um exemplo para o futuro) - como pudemos analisar, que, em primeira instância, são estranhos à da primeira edição - e uma monumentalização do amor para a eternidade, fisgado pela inspiração de que o imperador Adriano teria tido a ideia de uma imortalização de mortais através da arte (e sobretudo esculturas) de seu $\operatorname{amado}^{75}$. Contudo, ambas as formas de se reapropriar do passado são relativas aos respectivos contextos que tratamos.

A literatura seria um dos modos propostos por Huyssen ${ }^{76} \mathrm{e}$ Gumbrecht ${ }^{77}$ para explorar outras formas possíveis de narrar o tempo para além de compreender outras dimensões que não a historiografia tradicional. Pensando o caso de literaturas consideradas como pós-

${ }^{74}$ HEGEL, G. W. F.. Cursos de Estética: Volume III. Tradução de Marco Aurélio Werle e Oliver Tolle com consultoria de Victor Knoll. São Paulo: Editora da Universidade de São Paulo, 2002, pp. 111-159.

${ }_{75}^{75}$ Cf. LOZADA, Op. cit., pp. 192-193.

${ }^{76}$ HUYSSEN, Andreas. Culturas do passado-presente: modernismo, artes visuais, políticas da memória. Rio de Janeiro: Contraponto, 2014.

${ }^{77}$ GUMBRECHT, Hans Ulrich. Atmosfera, ambiência, stimmung: sobre um potencial oculto da literatura. 1. ed. Rio de Janeiro: Contraponto, 2014.

Revista Vernáculo n. ${ }^{\circ} 41$ - primeiro semestre /2018

ISSN 2317-4021 
coloniais, Durval Muniz ${ }^{78}$ traz para debate as possibilidades de registro e não-registro como meios de lidar com os traumas que marcaram o século passado. O não registro, menos transparente que o registro em si, é fundamental nas discussões acerca das marcas do tempo nas sociedades.

De modo geral, traumas e experiências no tempo atingem a subjetividade do sujeito, são interiorizados e passam a organizar o mundo e as temporalidades de cada sujeito, conforme afirma François Dosse $^{79}$. Contudo, essas mesmas formas múltiplas de experiência no tempo podem bloquear a inscrição e a sua expressão. $O$ silêncio é também uma maneira de se observar eventos traumáticos que podem convocar em si o esquecimento, bloquear o dizer e silenciar o sujeito. Esse silêncio, provocado internamente no sujeito ou por pressões externas, foi por muito tempo ignorado pela historiografia após os eventos, especialmente por parte de uma história nacional que buscava legitimar aqueles que estão no poder.

Neste sentido, a literatura possui um potencial fundamental no que se refere aos usos do passado, um papel que, como nos lembra Paul Ricoeur $^{80}$, situa-se entre o lembrar e o fazer esquecer. De forma ampla, obras literárias, onde o texto de Fernando Pessoa se insere, permeadas

78 ALBUQUERQUE JUNIOR, Durval Muniz de. As Sombras Brancas: Trauma, esquecimento e Usos do Passado. In: VARELLA, Flávia F. et al. (org.). Tempo Presente \& Usos do Passado. Rio de Janeiro: Editora FGV, 2012.

${ }^{79}$ DOSSE, François. Renascimento do acontecimento. São Paulo: Ed. da UNESP, 2013.

${ }^{80}$ RICOEUR, Paul. A memória, a história, o esquecimento. Campinas: Ed. da UNICAMP, 2008.

Revista Vernáculo n. ${ }^{\circ} 41$ - primeiro semestre $/ 2018$

ISSN 2317-4021 
por interesses e redes de comunicação, mobilizam passados diversos, partindo de referências e de formas de consciência que são moldadas pelos indivíduos no entrecruzamento do individual e do coletivo. Essa articulação faz lembrar, mas também promove o esquecimento e, acima de tudo, propõe uma ressignificação de elementos sociais, como, no caso estudado, a efebia e a homossexualidade.

\section{Referências}

ALBUQUERQUE JUNIOR, Durval Muniz de. As Sombras Brancas: Trauma, esquecimento e Usos do Passado. In: VARELLA, Flávia F. et al. (org.). Tempo Presente \& Usos do Passado. Rio de Janeiro: Editora FGV, 2012.

BACKE, Annika. Antinoos: Geliebter und Gott. Berlin: Staatliche Museen zu Berlin, Stiftung Preußischer Kulturbesitz, 2005.

BAILLY, A. et al. Dictionnaire Grec-Français. Paris: Hachette, 2000.

BLACKBURN, Simon. Dicionário Oxford de filosofia. Rio de Janeiro: Zahar, 1997.

BURKE, Peter. A Escola dos Annales (1929-1989): a Revolução Francesa da Historiografia. São Paulo: Fundação Editora da UNESP, 1997.

CARITÓN DE AFRODISIAS/ JENOFONTE DE ÉFESO. Quéreas y Calírroe / Efesíacas. Fragmentos novelescos. Madrid: Gredos, 1979.

CARTAS de Fernando Pessoa a João Gaspar Simões. Introdução, apêndice e notas do destinatário. Lisboa: Europa-América, 1957. 2. ${ }^{a}$ ed. Lisboa: Imprensa Nacional - Casa da Moeda, 1982.

CHARTIER, Roger. Leituras e leitores na França do Antigo Regime. São Paulo: UNESP, 2004.

DIFEL, 2002.

A história cultural: entre práticas e representações. Portugal:

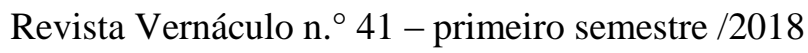

ISSN 2317-4021 
CLEMENTE DE ALEXANDRIA. Protreptikos pros Ellenas. Edição de G. W. Butterworth. Disponível em Perseus Digital Library: < http://www.perseus.tufts.edu/hopper/text?doc=Perseus:text:2008.01.0633> (acessado às 18 horas do dia 20 de dezembro de 2016).

COMMELIN, P. Mitologia Grega e Romana. São Paulo: Martins Fontes, 1993.

CUNHA, Maria Teresa Santos. Essa coisa de guardar... Homens de letras e acervos pessoais. História da Educação, Pelotas, v. 12, n. 25, p.109-130, Maio/Agosto 2008.

DE BARROS, Diana Luz Pessoa. Estudos do discurso. In: FIORIN, José Luiz (org.). Introdução à Linguística: II. Princípios de análise. São Paulo: contexto, 2012.

DESSA, Hermann. Inscriptiones Latinae Selectae (ILS), nº 7212, 1892-1916.

DIONÍSIO, João. Introdução. Poemas Ingleses. Antinous, Inscriptions, Epithalamium, 35Sonnets. Edição Crítica de Fernando Pessoa, Série Maior, Vol. V, tomo 1. Ed. João Dionísio. Lisboa: IN-CM, 1993.

DOSSE, François. Renascimento do acontecimento. São Paulo: Ed. da UNESP, 2013.

FERREIRA, Antonio Celso. A fonte fecunda. In: PINSKY, Carla; LUCA, Tânia (orgs.). O historiador e suas fontes. São Paulo: contexto, 2009.

FISHER, Nick. Aeschines: Against Timarchos. Oxford University Press, 2001.

GADAMER, Hans-Georg. Verdade e Método I: traços fundamentais de uma hermenêutica filosófica. Rio de Janeiro: Vozes, 2013.

- Hermenêutica da obra de arte. Trad. de Marco

Casanova. São Paulo: Martins Fontes, 2010.

GUMBRECHT, Hans Ulrich. Atmosfera, ambiência, stimmung: sobre um potencial oculto da literatura. 1. ed. Rio de Janeiro: Contraponto, 2014.

HEGEL, G. W. F. Cursos de Estética: Volume III. Tradução de Marco Aurélio Werle e Oliver Tolle com consultoria de Victor Knoll. São Paulo: Editora da Universidade de São Paulo, 2002.

Revista Vernáculo n. ${ }^{\circ} 41$ - primeiro semestre /2018

ISSN 2317-4021 
HEITICH, Paulo Ricardo. Paul Ricoeur: A Tríplice Mímese. In: Problemas filosóficos da contemporaneidade. ANAIS - IX SEMANA ACADÊMICA DE FILOSOFIA UNICENTRO, 2010.

HERÓDOTO. História. Trad. de Mário da Gama Kury. Brasília: UNB, 1985.

HOFMANN, Albert; GORDON, Wasson R.; RUCK, Carl. El camino a Eleusis: una solución al enigma de los misterios. México: Fondo de Cultura Económica, 1993.

HOMERO. Odisseia. Ed. Bilíngue. Trad. de Trajano Vieira. São Paulo: Editora 34, 2012.

HOWES, Robert. Portugal. In: Gay Histories and Cultures: An Encyclopedia. Vol. 2. Ed. George Haggerty. New York: Garland, 2000.

HUYSSEN, Andreas. Culturas do passado-presente: modernismo, artes visuais, políticas da memória. Rio de Janeiro: Contraponto, 2014.

JAKOBSON, Roman. Os oxímoros dialéticos de Fernando Pessoa. Trad. de Haroldo de Campos. In: SAUSSURE; JAKOBSON; HJELMSLEV; CHOMSKY. Textos selecionados. Coleção “Os Pensadores”. São Paulo: Abril Cultural, 1978.

KLOBUCKA, Anna M.Fernando Pessoa ativista queer: Uma releitura do 'Antinous'. University of Massachusetts Dartmouth. III CONGRESSO INTERNACIONAL FERNANDO PESSOA, Lisboa, 28-30 de novembro de 2013. Disponível em: <https://umassd.academia.edu/AnnaMKlobucka> (acessado em 05 de Janeiro de 2017 às 11:59).

LAMBERT, Royston. Beloved and God: The Story of Hadrian and Antinous. George Weidenfeld \& Nicolson, 1984.

LE GOFF, Jacques. Documento/Monumento. In: LE GOFF, Jacques. História e Memória. 5. ed. Campinas: Ed. Unicamp, 2003.

LOZADA, Jorge Alberto Uribe. Um Drama Da Crítica: Oscar Wilde, Walter Pater e Matthew Arnold, Lidos por Fernando Pessoa. Doutoramento em Estudos da Literatura e da Cultura (Teoria da Literatura). Lisboa: Universidade de Lisboa, 2014. 
LYONS, John. Linguistique générale: introduction à la linguistique théorique. Trad. de F. Dubois-Charlier et D. Robinson. Paris: Larousse, 1970.

MOISÉS, Carlos Felipe. O Poema e As Máscaras: introdução à poesia de Fernando Pessoa. Florianópolis: Letras contemporâneas, 1999.

NUSSBAUM, Martha. The Fragility of Goodness. Cambridge University Press, 2001.

PANZANELLI, Roberta; SCHMIDT, Eike; LAPATIN, Kenneth (eds.). The Color of Life: Polychromy in Sculpture from Antiquity to the Present. Los Angeles: Getty Research Institute, 2008.

PlATÃo. Diálogos: O Banquete - Fédon - Sofista - Político. Trad. de José Cavalcante de Souza, Jorge Paleikat e João Cruz Costa. São Paulo: Abril Cultural, 1972.

PAUSÂNIAS. Pausanias Description of Greece with an English Translation by W.H.S. Jones, Litt. D., and H.A. Ormerod, M.A., in 4 Volumes. Cambridge, MA, Harvard University Press; London, William Heinemann Ltd., 1918.

PESAVENTO, Sandra J. História e história cultural. Belo Horizonte: Autêntica, 2014.

PESSOA, Fernando. Obra poética. Organização, tradução e notas de Maria Aliete Galhoz. Rio de Janeiro: Editora Nova Aguilar S.A., 1977. . Obra poética. Rio de Janeiro: Aguillar, 1974. . Páginas de Doutrina Estética. Lisboa, 1946.

RICOEUR, Paul. Tempo e Narrativa: vol. 2. A configuração do tempo na narrativa de ficção. Trad. de Márcia Valéria Martinez de Aguiar e revisão de Claudia Berliner. São Paulo: Martins Fontes, 2012.

A memória, a história, o esquecimento. Campinas: Ed. da UNICAMP, 2008. . A Metáfora Viva. São Paulo: Loyola, 2005.

ROBB, Graham. Strangers: Homosexual Love in the Nineteenth Century. New York \& London: W. W. Norton, 2003.

Revista Vernáculo n. ${ }^{\circ} 41$ - primeiro semestre /2018

ISSN 2317-4021 
SIRINELLI, Jean-François. Abrir a história: novos olhares sobre o século XX francês. Belo Horizonte: Autêntica, 2014.

SALLES, Luciana. Jorge de Sena. Convergência Lusíada, v. 27, p. 135-138, 2012.

SAUSSURE, Ferdinand de. Curso de Linguística geral. São Paulo: Cultrix/Edusp, 1969.

VIDAL-NAQUET, Pierre; VERNANT, Jean-Pierre. Mito e Tragédia na Grécia Clássica. Trad. por Maria da Conceição M. Cavalcante. São Paulo: Perspectiva, 1999, p. 125-145.

WATERS, Sarah. 'The Most Famous Fairy in History': Antinous and Homosexual Fantasy. Journal of the History of Sexuality 6:2 (1995), 194-230.

WILDE, Oscar. Retrato de Dorian Gray. Ed. bilíngue. Trad. de Marcella Furtado. São Paulo: Landmark, 2009.

. The Sphinx. In: Collected Poems. Disponível em : <https://ebooks.adelaide.edu.au/w/wilde/oscar/w67p/chapter15.html > (acessado às 18:16 de 09/04/2017). Web edition published by: eBooks@Adelaide. South Australia: The University of Adelaide Library. 1894.

YOURCENAR, Marguerite. Mémoires d'Hadrien. Paris: Plon, 1951.

Recebido em 12/04/2017, aceito para publicação em 18/09/2017.

Revista Vernáculo n. ${ }^{\circ} 41$ - primeiro semestre /2018

ISSN 2317-4021 